\title{
Open Access Journals - The way forward for out-of-hospital research publications
}

\author{
Dr Malcolm Boyle \\ Affiliation: \\ Editor, Australasian Journal of Paramedicine
}

The open access journal is becoming a common place to publish compared to the traditional paper based journal as the work is readily available to the research and general community. The academic community place a lot of emphasis on the quality and impact factor of journals. There are numerous problems with this stance especially for academic paramedics and the general out-of-hospital healthcare provider. Some in the academic community look upon open access journals as not being "proper" or "lacking in quality". In the majority of instances this is not the case as the open access journals have comparable international editorial boards who oversee the manuscript handling processes.

When I refer to the out-of-hospital sector I use this in a general sense to cover all aspects of the outof-hospital operational and research areas, including but not confined to, clinical practice, education, management, policy, the list goes on.

For those academic healthcare researchers hell bent on publishing in the best journal with the highest impact factor, they need to look at some of the open access journals as their impact factors are often higher than their paper based counterparts. This has likely come about because of the ease of access to articles and researcher willingness to cite work from the open access journals. The downfall of publishing in some open access journals is the rather high fees charged for "processing" the manuscript.

The broad range of health related areas covered by the out-of-hospital sector is vast compared to many specialist health related fields, for example, surgery, which have a select number of journals were the majority will seek to publish. Out-ofhospital sector researchers and clinicians seek to publish in journals relevant to their area of research where their work will be read and recognised by the wider research community, managers, and policy makers.
Out-of-hospital healthcare providers are unlikely to subscribe to more than one journal, and many will not subscribe to any journal. Therefore if outof-hospital researchers want their work to be read and used in improving practices and outcomes then journals with open access are the place to publish.

A recent article in "The Conversation" by Professor Warwick Anderson, Chief Executive Office of the National Health and Medical Research Council (NH\&MRC), highlighted that research funded by them and the Australian Research Council, should be "openly accessible" by the community. Professor Anderson also highlighted that the NH\&MRC had not used impact factors or the journal prestige as a means of determining a researcher's output quality since 2008. Professor Anderson supports researchers publishing in a journal that will have the greatest impact on the readership and therefore the area of interest compared to the best journal which few people may read.(1)

Open access journals have many pluses, including, that anyone can access the article and read it, there are few limits associated with the manuscript (no page, references, tables, or figures limits), colour images are accepted and do not attract an additional publication charge, in most cases manuscripts are published quicker, and the article can be read and downloaded using any web browser. One of the downsides is some open access publishers charge considerable fees (up to $\$ A U D 2,500$ ) to publish the article, however, there are many open access publishers which do not charge or charge small manuscript processing fees, for example \$AUD250.

So to the converted we continue publishing in open access journals, like the Australasian Journal of Paramedicine, and to the academic "snobs" you need to see the light and get with the times. 
In this issue the articles cover a range of topics, some which have not been published in the Australian literature before. The article by Kylie O'Brien and colleagues is about work readiness of final year paramedic students, one of the first studies of its kind in Australia.(2) The article by Linda Ross reports on the findings of a literature review about rapport with "real patients" for developing communication skills in healthcare professional education, something relevant to paramedic educators. This study is part of a suite of undergraduate paramedic education related research emanating from universities in Australia.(3) Anna Hall and her colleagues have reviewed the literature about the experiences of bystanders after a motor vehicle accident and have identified some of the issues bystanders experience during and after the incident, something most paramedics do not consider when at, or after departing, the incident.(4) Gavin Smith and Jeff Kenneally have written about the process behind Ambulance Victoria's Clinical Practice Guideline development and change process using the recent change to the management of supraventricular tachycardia.(5) Alana Prosser and her colleagues have provided some insight into the general public of Western Australia and their perception of the cost of an ambulance trip, issues with ambulance cover, and the use of a ambulance. (6)

The AJP now has a Twitter account, @ajparamedicine, where all publications will be announced and articles from each issue highlighted. The use of social media is to ensure there is a wide distribution of information about the journal and the articles it publishes in a timely manner.

We have published the Paramedics Australasia 2011 and 2012 conference abstracts in October. In mid January 2014 we look forward to publishing the Paramedics Australasia 2013 conference abstracts.

The first issue for 2014 will be published on the first Monday, the $3^{\text {rd }}$, of February 2014 and will have a theme of simulation in which we are well advanced with the peer reviewing of prospective manuscripts.

This is the last issue for 2013, and on behalf of the editorial team I would like to wish the readership a happy and safe Christmas and New Year holiday period and look forward to your ongoing support of the journal in 2014 as we strive to improve all aspects of the journal.

\section{REFERENCES}

1. Anderson W. Quality not quantity: measuring the impact of published research The Conversation2013 [30th October 2013]. Available from: http://theconversation.com/quality-notquantity-measuring-the-impact-of-publishedresearch-18270.

2. O'Brien K, Moore A, Hartley P, Dawson D. Lessons about work readiness from final year paramedic students in an Australian university. Australasian Journal of Paramedicine. 2013;10(4).

3. Ross L. Facilitating Rapport through Real Patient Encounters in Health Care Professional Education. Australasian Journal of Paramedicine. 2013;10(4).

4. Hall A, Wootton K, Hutton A. Bystander Experiences at and after a Motor Vehicle Accident: A review of the literature. Australasian Journal of Paramedicine. 2013;10(4).

5. Smith G, Kenneally J. Development and implementation of Victorian prehospital Clinical Practice Guidelines: The supraventricular tachycardia example. Australasian Journal of Paramedicine. 2013;10(4).

6. Prosser A, Prosser J, Playford D. Rural Residents' Perception about the Coverage, Cost and Access of Ambulance Services. Australasian Journal of Paramedicine. 2013;10(4). 